\title{
Development and validation of a simples and fast method for sulfonamides, tetracyclines and macrolides in honey using LC-MS/MS
}

\author{
Cristina Belíssimo Ribeiro*a Magda Targa Martins ${ }^{\text {a }}$ Louise Jank ${ }^{\text {a }}$ Juliana Bazzan ${ }^{\text {a }}$ Arsand ${ }^{\text {a }}$ Rodrigo \\ Barcellos Hoff ${ }^{\mathrm{a}}$ Fabiano Barreto ${ }^{\mathrm{a}}$
}

\author{
${ }^{a}$ Laboratorio Nacional Agropecuário-LANAGRO/RS, Ministério da Agricultura Pecuéaria e Abastecimento Porto Alegre, RS, \\ Brazil. Ministério da Agricultura Pecuéaria e Abastecimento \\ Estr. Ponta Grossa, 3036 - Ponta Grossa, Porto Alegre - RS, 91770-010
}

*Corresponding author: cristina.ribeiro@agricultura.gov.br

\begin{abstract}
Antibacterial are widely used in apiculture applications for diseases treatment and prophilatic purposes. Inadequate uses of these drugs can lead of undesirable residues in honey for consumption. In Brazil, the legal authorities set a maximum residue limit (MRL) for different compound in honey, ranging from 10 to $20 \mathrm{ng} \mathrm{ml}^{-1}$. The monitoring of antibacterials is a concern, since it constitutes a risk to human health and collaborates with the growth of resistant bacteria. Brazil has the National Residue Control Plan (NRCP) to ensure that the products traded are compliant with the safety and quality criteria required by consumers. The goal of this work was to develop and validate a method suitable to determine sulfonamides, tetracyclines and macrolides in honey, using liquid chromatography tandem mass spectrometry. The main objective was to develop an efficient technique, combining simplicity, speed and low cost, since the method will be employed in routine analysis. Recoveries between 36 to $139 \%$ were obtained. Good linearity $\left(\mathrm{r}^{2}\right)$ above 0.95 , considering three different days, for all drugs was achieved in concentrations ranging from 0 to $200 \%$ of the MRL. Intraday and inter-day precision with CV\% $(n=6)$ lower than $20 \%$, in agreement with specifications were obtained in concentrations ranging from 0.5 to $1.5 \mathrm{MRL}$, except for tetracycline and erythromycin. Accuracy was between 89 to $113 \%$. Limits of quantitation for macrolides were $2.5 \mathrm{ng} \mathrm{g}^{-1}$ and for sulfonamides and tetracyclines were $5 \mathrm{ng} \mathrm{g}^{-1}$. Decision limit $\left(\mathrm{CC}_{\alpha}\right)$ was evaluated and the results obtained were between 12.9 to $28.1 \mathrm{ng} \mathrm{g}^{-1}$. The detection capability $\left(\mathrm{CC}_{\beta}\right)$ obtained was between 15.8 to $36.3 \mathrm{ng} \mathrm{g}^{-1}$. The proposed method demonstrated to be suitable for this intended purpose and will contribute to antibacterial honey monitoring.
\end{abstract}

Keywords: sulfonamides, tetracyclines, macrolides, validation, LC-MS/MS, residues.

\section{Introduction}

Antibacterials are commonly used in livestock production to maintain health and productivity. The most commonly used antibiotic in food producing animals are $\beta$-lactams, tetracyclines, aminoglycosides, lincosamides, macrolides and sulfonamides. The use of antibacterials in foodproducing animals may leave residues in foodstuffs of animal origin like meat, milk, honey and eggs (Lee et al., 2001; Kibroyesfa and Naol, 2017). Honey is one of the healthy food across the world used for thousands of years in world- wide, being rich in minerals, antioxidants, and simple sugars (Kivrak et al., 2016). Sulfonamides, tetracyclines, nitrofurans and macrolides are used to prevent and combat diseases in bees, and the use of these substances has been known since 1940 (Benetti et al., 2006; Barganska et al., 2011). Beekeepers use antibiacterials at relatively high doses to treat infections, or at low doses as "growth promoters" (Al-Waili et al., 2012). The emergence of resistant bacteria, other antibacterials can be also used, like erytromycin, lincomycin, monensin, streptomycin and enrofloxacin (Boeckel et al., 2015). Residues of these antibacterials can remain and accumulate in honey and is a risck to human health and could be an importante vehicle for development of bacterial resistance. Antibacterials residues have a relatively long half life and may have direct toxic effects on consumers (Baquero et al., 2008; AlWaili et al., 2012). Safety of food is one of the main objectives in consumer health policy, so Maximum Residue Limits (MRLs) have been established for most foods produced by animals, (Barganska et al., 2011; Boeckel et al., 2015). In European Union there are no MRLs established for bee products such as honey. In some countries MRLs have been set for different classes of antibacterials ranging from 10 to $50 \mathrm{ng}$ g- 1 (Hammel et al., 2008). According to Ministery of Agriculture, Livestock and Supply in Normative Instruction (IN/09/2017), the limits established for tetracyclines are $20 \mathrm{ng}$ g-1 (the sum of 
tetracyclines), sulfonamides are $20 \mathrm{ng}$ g-1 (the sum of slfonamides) and for macrolides are $10 \mathrm{ng}$ $\mathrm{g}-1$. The use of antibacterials in food production is restricted and must be minimized, thus is imperative to monitor these substances in honey, developing methos for its purpose.

LC-MS/MS has become widely used in veterinary drug residue analysis in different foods. Multiclass methods can be developed with high selectivity and sensitivity, complaning a large number of analytes from different classes, especially when the multiple-reaction monitoring mode (MRM) is addopted (Berendsen et al., 2013). According to European Union (EU) criteria, two transitions have to be monitored to guarantee the confirmation of the analytes (2002/657/EC). In Brazil, the National Residue Control Plan (NRCP) is in strict agreement with the 2002/657/EC Commission Decision (Brasil, 2011).

Considering the complexity of honey matrix, sample preparation is a challenge. Several methods were described in the literature about antibacterial residues in honey, but there are few reports for multiclass methods for this matrix. Kivrak et al. (2016), developed a method for amphenicols and sulfonamides in honey, using dissolution with acetic acid $0.5 \%$ and ultrasonic bath at $50{ }^{\circ} \mathrm{C}$ for 30 minutes. The analysis of sulfonamides and chloranphenicol in honey was developed, using Solid-Phase Extraction (SPE) (Sheridan et al., 2008). A method using aciidic hydrolysis and SPE for sulfonamides, tetracyclines and flumequine determination was developed by Kaufmann et al. (2002). Benetti et al. (2011), demonstrated a method for lincomycin and macrolides in honey using SPE. Another work presented a method for determination of 27 antibiotics in honey including sulfonamides, nitroimidazole and quinolones. The extraction procedure involves acidic hydrolysis of honey followed by a double purification step (SPE) (Galarini et al., 2015). Lopez and colaborators (2008) developed a method for tetracyclines, fluoroquinolones, macrolides, aminoglycosides, sulfonamides, phenicols, fumagilin and erythromycin usind dissolution of honey in water. The supernatant was filtered and cleaned by SPE. Macrolides, tetracyclines, quinolones and sulfonamides were analyzed through a method using dissolution of honey with EDTA followed by SPE (Martinez-Vidal et al., 2009). Hammel and contributors (2008), developed a method for 42 antibiotics in honey including tetracyclines, macrolides, aminoglycosides, beta-lactams, amphenicols and sulfonamides using four liquid/liquid extraction steps, they used a stacking injection procedure. Quick, Easy, Cheap, Effective, Rugged and Safe (QuEChERS) became very popular for pesticides determination, especially in food matrices and was also used to determine chloramphenicol in honey (Pan et al., 2006).

The goal of this work was to determine Tetracyclines (TCs) [doxycycline (DOXY), oxitetracycline (OTC), chlortetracycline (CTC)]; Sulfonamides (SAs) [sulfathiazole (STZ), sulfamethazine (SMZ), sulfadimethoxine (SDMX)]; and macrolides (MACROs) [erythromycin (ERY) and Tylosin (TYL)]. Demeclocycline (DMC), Sulfapyridine (SPY) and Roxythromycin (ROXY) were used as internal standards (IS). The extraction procedure developed was considered very easy, cheap and fast, thus, suitable for routine analyzes involving a large number of samples.

\section{Material and methods}

\section{Standards}

Standards of sulfatiazole (STZ), sulfamethazine (SMZ), sulfadimethoxine (SDMX), tetracycline (TC), oxytetracycline (OTC), chlortetracycline (CTC), doxycycline (DOXY) and the internal standards, sulfapyridine (SPY), demeclocycline (DMC) were purchased from Riedel-de-Haen (Buchs, Switzerland) or Sigma-Aldrich (St. Louis, MO, USA). Erythromycin (ERY), tylosyn (TYL) and roxythromycin (ROXY) were obtained from Sigma-Aldrich Logistik (Scnelldorf, Germany) all with $>95 \%$ certified purity.

Stock standard solutions of STZ, SMZ, SDMX, TC, CTC, DOXY were prepared in methanol at concentrations of $1.0 \mathrm{mg} \mathrm{ml}^{-1}$. Internal standards SPY and DTC were prepared in the same way as the other solutions of TCs and SAs. For MACROs the solution were prepared in water:acetonitrile (50:50) to achieve the final concentration of $1.0 \mathrm{mg} \mathrm{ml}^{-1}$ and the same was made for internal standard ROXY. 
The working solution was prepared in methanol to obtain a final concentration of $2 \mu \mathrm{g}$ $\mathrm{ml}^{-1}$ for TCs and SAs and $1 \mu \mathrm{g} \mathrm{ml}^{-1}$ for MACROs. Working solution for internal standards was prepared in methanol to achieve a final concentration of $2 \mu \mathrm{g} \mathrm{ml}^{-1}$ for DTC and SPY and $1 \mu \mathrm{g} \mathrm{ml}^{-1}$ for ROXY. Stock solutions were stored at $-20{ }^{\circ} \mathrm{C}$ and were stable, at least, for six months. Working solutions were stored at $5{ }^{\circ} \mathrm{C}$ and were considered stable for, at least, three months.

\section{Reagents and Chemicals}

Except when indicated, all reagents were of HPLC grade. Acetonitrile was purchased from J.T.Baker (Phillipsburg, NJ, USA) and methanol was purchased from Merck (Darmstadt, Germany). Formic acid was of HPLC grade J.T.Baker (Phillipsburg, NJ, USA). Ultrapure deionized water was produced by a Milli-Q apparatus (Millipore, Bedford, MA, US). Dissodium ethylenediaminetetracetate $\left(\mathrm{Na}_{2}\right.$ EDTA) was obtained from Sigma.

\section{$L C-M S / M S$}

The LC-MS/MS measurements were performed using an Agilent 1100 Series chromatographic system coupled to an AB Sciex API 5000 triple quadrupole mass spectrometer with an electrospray source in positive ionization mode. Compound optimization parameters were achieved through infusion of each standard solution of target compounds with a flow injection of $10 \mu \mathrm{l} \mathrm{min}{ }^{-1}$, using flow injection analysis (FIA). Acquisition was carried out in multiple Reaction Monitoring (MRM) mode. Data processing was performed in Analyst 1.6.1 software. Separation was achieved in a XTerra ${ }^{\circledR} \mathrm{C}_{18}$ endcapped column $3.5 \mathrm{~mm}, 125 \mathrm{~A}^{\circ}(100 \mathrm{~mm} \times 2.1 \mathrm{~mm})$ from Waters. A Phenomenex $\mathrm{C}_{18}$ column $(4.0 \mathrm{~mm} \times 3.0 \mathrm{~mm})$ was used as guard column. The gradient optimized for the analytes separation starts keeping 98\% A (water with $0.1 \%$ formic acid) and $2 \% \mathrm{~B}$ (acetonitrile with $0.1 \%$ formic acid) decreasing linearly to $20 \%$ (A) in 6 min. After that, decreases to $10 \%$ (A) in 4 min and than to $2 \%$ (A) in 3 min. After this period, the initial proportion of $98 \%$ (A) was reestablished in $2 \mathrm{~min}$, with a total run time of $15 \mathrm{~min}$.
Between each analysis, 4 min of equilibration time is applied, using the initial gradient conditions $98 \%$ (A). The mobile phase flow rate was $0.3 \mathrm{ml} \mathrm{m^{-1 }}$. Optimized mass spectrometry parameters for each compound are shown in Table 1.

Table 1. Optimezed mass spectrometry parameters for each compouds and their retention times (Rt).

\begin{tabular}{|c|c|c|c|}
\hline Analyte & $\begin{array}{l}\text { Precursor ion } \\
\qquad(\mathbf{m} / \mathbf{z})\end{array}$ & $\begin{array}{l}\text { Product ion } \\
(\mathrm{m} / \mathrm{z})\end{array}$ & Rt (min) \\
\hline DOXY1 & 445,125 & 428,100 & 5.95 \\
\hline DOXY2 & 445,125 & 154,000 & - \\
\hline OTC 1 & 461,100 & 426,300 & 5.32 \\
\hline OTC 2 & 461,100 & 444,300 & - \\
\hline DMC 1 & 465,400 & 448,300 & 5.60 \\
\hline DMC 2 & 465,400 & 430,100 & - \\
\hline CTC 1 & 479,200 & 444,200 & 5.82 \\
\hline CTC 2 & 479,200 & 462,200 & - \\
\hline TC 1 & 445,100 & 154,000 & 5.72 \\
\hline TC 2 & 445,100 & 410,000 & - \\
\hline SPY 1 & 250,100 & 156,000 & 5.26 \\
\hline SPY 2 & 250,100 & 108,000 & - \\
\hline STZ 1 & 256,000 & 156,100 & 5.25 \\
\hline STZ 2 & 256,000 & 108,200 & - \\
\hline SMZ 1 & 279,100 & 108,000 & 5.75 \\
\hline SMZ 2 & 279,100 & 92,100 & - \\
\hline SDMX 1 & 311,200 & 156,100 & 6.78 \\
\hline SDMX 2 & 311,200 & 108,200 & - \\
\hline ERY 1 & 734,000 & 158,100 & 6.23 \\
\hline ERY 2 & 734,000 & 576,000 & - \\
\hline TYL 1 & 916,000 & 174,000 & 6.46 \\
\hline TYL 2 & 916,000 & 101,000 & - \\
\hline ROXY 1 & 837,626 & 158,000 & 5.95 \\
\hline ROXY 2 & 837,626 & 679,400 & - \\
\hline
\end{tabular}




\section{Honey Samples}

The method was validated with honey samples obtained by different producers collected by Federal Inspection Service (FIS) and obtained from local markets. Method specificity/selectivity was performed using 20 different honey samples, and then method applicability were taken from 108 different samples since 2016, when the method started to be used in the laboratory routine for honey analysis.

\section{Sample Preparation}

An aliquot of $10 \mathrm{~g}$ of honey were transferred into a $50 \mathrm{ml}$ polypropylene centrifuge tube. The samples were spiked with the internal standard working solution and working solution containing all analytes. The samples were homogenized in a vortex and $4.5 \mathrm{ml}$ of MilliQ water were added. The samples were kept in a stove for $20 \mathrm{~min}\left(45^{\circ} \mathrm{C}\right)$. All samples were mixed in a vortex and $500 \mu \mathrm{l}$ of EDTA was added. The samples were kept for 10 minutes protected from light. Then, $10 \mathrm{ml}$ of acetonitrile were added and the samples were mixed in a shaker during $20 \mathrm{~min}$ and centrifuged for $10 \mathrm{~min}$, at approximately 4000 $\mathrm{rpm}$, at $5{ }^{\circ} \mathrm{C}$. The supernatand was transferred to another polypropylene centrifuge tube and evaporated to approximately achieve $200 \mu \mathrm{l}$. After that, $2 \mathrm{ml}$ of water:acetonitrile (70:30) were added, the samples were mixed in a vortex and transferred to a vial. An aliquot of $10 \mu \mathrm{l}$ was injected into the LC-MS/MS system.

\section{Method Validation}

Method validation was carried out following the Commission Decision 2002/657/EC. The performance characteristics for quantitative methods evaluated were: recovery, selectivity/specificity, linearity, precision (intraday/interday), accuracy, limit of quantitation (LOQ), decision limit ( $\mathrm{cc} \alpha$ ), detection capability $(\operatorname{cc} \beta)$ and applicability. The validation procedure included the analysis of 21 blank samples spiked with analytes of interest. The calibration curve includes six points corresponding to $0,25,50$, 100, 150 and 200\% MRL. Besides, 3 samples called "tissue standard", that is an amount of the analytes in the MRL value added after the extraction procedure, a blank sample and a calibration curve prepared just in solvent. This experiment was repeated in three different days. Besides, honey samples spiked with internal standards $(n=20)$ were analyzed through the presented method to verify the specificity/selectivity. For applicability, samples received from FIS $(n=108)$ were analyzed.

\section{Results and Discussion}

Food security is important to ensure that people are not consuming unwanted substances in their diet. Residues of antibacterials may be present in some foods as a result of veterinary practices to treat and prevent diseases in animals. SAs, TCs and MACROs are applied by beekeepers to prevent and combat diseases in honeybees (Kummerer et al., 2009; Barganska et al., 2011). In this work, important representatives of the classes of SAs (STZ, SMZ, SDMX), TCs (TC, OTC, DOXY, CTC) and MACROs (ERY, TYL) were included in a validated method capable to quantify these drugs in a short space of time, using a small amount of solvent, allowing satisfactory results. For SAs, is described in the literature the importance of acid conditions to prevent the bounding with the sugar moieties, but it was discarded in the present method, since macrolides may be sensitive to this condition (Hammel et al., 2008). The use of water and the maintenance in the heat allowed the dissolution of the honey. EDTA is described to be essential for tetracyclines extraction, avoiding the formation of chelates with divalent metals (Anderson et al., 2005). The choice of extraction solvent for multiresidue methods is fundamental to achieve the desired result. Acetonitrile enables the extraction of a wide range of analytes of different polarities, avoiding the co-extraction of lipophilic compounds such as waxes, fats and pigments (Lehotay et al., 2001; Prestes et al., 2009). A liquid-liquid extraction (LLE) using ACN demonstrated good recoveries for almost all analytes as demonstrated in Table 2, except for SDMX and ERY, that presented $126 \%$ and $36 \%$, respectively. However, in multiclass method, is important to develop a generic method, which may be satisfactory for most substances, but will not always be the best for them separately. Thus, considering that honey presents many interferers in its constitution, the calibration curve in the 
routine analysis will be ever realized in matrix. Steps of centrifugation became important to promote a cleanest extract. Sample concentration was very important because the limits set are very small.

Table 2. Recoveries obtained for all analytes trhough the presented extraction procedure.

\begin{tabular}{cc}
\hline Analyte & Recovery $(\%)$ \\
\hline DOXY & 100 \\
OTC & 55 \\
CTC & 80 \\
TETRA & 68 \\
STZ & 93 \\
SMZ & 90 \\
SDMX & 139 \\
ERY & 36 \\
TYL & 93 \\
\hline
\end{tabular}

LC-MS/MS using two transitions for each analyte in MRM mode is a specific technique. The identification points (IPs) required by European Community are achieved through precursor ion (1.0 IP), quantifier ion (1.5 IP) and qualifier ion (1.5 IP) (657/EC/2002). The analysis of 20 different samples demonstrated that this method is capable to anlyze the proposed antibacterials without interference of endogenous substances (Figure 1).



Figure 1. Blank sample (A), Tissue standard sample at MRL (B), Fortified sample at MRL (C) and Analyzed sample with the IS (D).

The Total Ion Chromatography (TIC) of all analytes at the MRL value is demonstrated in
Figure 1. Good linearity $\left(\mathrm{r}^{2}\right)$ above 0.95 , considering three different days, for all drugs was achieved in concentrations ranging from $0 \%$ to 200\% MRL and is demonstrated in Table 3.

Table 3. Linearity of all analytes at three different days.

\begin{tabular}{lcccc}
\hline & \multicolumn{4}{c}{ Linearity $\left(\mathbf{R}^{\mathbf{2}}\right)$} \\
\hline Analyte & Conc $\left(\mathbf{n g ~ g}^{-\mathbf{1}}\right)$ & Day $\mathbf{1}$ & Day 2 & Day 3 \\
DOXY & $(0-40)$ & 0.9586 & 0.9602 & 0.9693 \\
OTC & $(0-40)$ & 0.9586 & 0.9653 & 0.9657 \\
CTC & $(0-40)$ & 0.9566 & 0.9775 & 0.9662 \\
TETRA & $(0-40)$ & 0.9914 & 0.9608 & 0.9541 \\
STZ & $(0-40)$ & 0.9942 & 0.9866 & 0.9959 \\
SMZ & $(0-40)$ & 0.9614 & 0.9939 & 0.9969 \\
SDMX & $(0-40)$ & 0.9942 & 0.9896 & 0.9898 \\
ERY & $(0-20)$ & 0.9641 & 0.9817 & 0.9900 \\
TYL & $(0-20)$ & 0.9812 & 0.9923 & 0.9887 \\
\hline
\end{tabular}

Intraday and interday precision with $\mathrm{CV} \%$ $(\mathrm{n}=6)$ lower than $20 \%$ (recommended for concentrations between $10 \mu \mathrm{g} \mathrm{kg}^{-1}$ and $100 \mu \mathrm{g} \mathrm{kg}$ ${ }^{1}$ ) in agreement with specifications for almost all analytes were achieved, except for TETRA and ERY that presents a value of 22.7 and $28.7 \%$ at 10 $\mu \mathrm{g} \mathrm{kg}$ (657/EC/2002), respectively. All the results are demonstrated in Table 4. According to Council Directive 657 of European Commission (2002), the coefficients of Variation (CV\%) should be lower than $32 \%$, using the Horwitz equation for reproducibility in the concentration of $10 \mu \mathrm{g} \mathrm{kg}^{-1}$. Even though the intermediate precision of ERY and TETRA were slightly higher than recommended, $35.4 \%$ and $34.7 \%$, respectively, the presented method was implanted in the routine of the laboratory to meet the demand related to honey monitoring. Accuracy was between 89 to $113 \%$ in accordance with the requirements established by $657 / \mathrm{EC} / 2002$. 
Table 4. Intraday precision, Inter-day precision and accuracy for all analytes.

\begin{tabular}{|c|c|c|c|c|c|c|c|c|c|}
\hline \multirow[b]{2}{*}{ Analyte } & \multicolumn{3}{|c|}{ Intraday Precision (\%) } & \multicolumn{3}{|c|}{ Interday Precision (\%) } & \multicolumn{3}{|c|}{ Accuracy (\%) } \\
\hline & 0.5 MRI & 1.0 MRL & $1.5 \mathrm{MRL}$ & 0.5 MRI & 1.0 MRL & $1.5 \mathrm{MRL}$ & 0.5 MRI & 1.0 MRL & 1.5 MRL \\
\hline DOXY & 12.2 & 12.3 & 13.5 & 3.8 & 3.3 & 4.5 & 108 & 108 & 108 \\
\hline OTC & 14.2 & 12.0 & 15.0 & 12.4 & 13.1 & 6.3 & 110 & 102 & 106 \\
\hline CTC & 15.0 & 12.2 & 14.0 & 13.8 & 8.3 & 2.7 & 108 & 100 & 100 \\
\hline TETRA & 22.7 & 17.5 & 14.3 & 27.2 & 4.2 & 2.9 & 103 & 104 & 110 \\
\hline STZ & 6.8 & 6.1 & 4.5 & 5.5 & 4.1 & 6.4 & 109 & 106 & 110 \\
\hline SMZ & 7.2 & 10.5 & 9.3 & 2.3 & 4.8 & 11.0 & 113 & 108 & 112 \\
\hline SDMX & 5.9 & 5.5 & 6.8 & 2.3 & 3.0 & 5.8 & 102 & 96 & 95 \\
\hline ERY & 16.8 & 19.6 & 16.3 & 17.3 & 28.7 & 25.1 & 96 & 97 & 89 \\
\hline TYL & 12.0 & 13.0 & 12.1 & 3.5 & 11.7 & 8.8 & 111 & 104 & 104 \\
\hline
\end{tabular}

Limits of quantitation (LOQ) for macrolides were $2.5 \mathrm{ng} \mathrm{g}^{-1}$ and for sulfonamides and tetracyclines were $5 \mathrm{ng} \mathrm{g}^{-1}$. Decision limit $\left(\mathrm{CC}_{\alpha}\right)$ that is the probability of a false noncompliance $<5 \%$ and detection capability $\left(\mathrm{CC}_{\beta}\right)$ that is the probability of a false compliance $<5 \%$ were determined. These results are demonstrated in Table 5.

Table 5. Decision limit $\left(\mathrm{CC}_{\alpha}\right)$, detection capability $\left(\mathrm{CC}_{\beta}\right)$ and LOQ for all antibacterials.

\begin{tabular}{lccc}
\hline Analyte & LOQ $\left(\mathrm{ng} \mathrm{g}^{-1}\right.$ & $\mathbf{C C} \boldsymbol{\alpha}\left(\mathrm{ng} \mathrm{g}^{-1}\right)$ & $\mathbf{C C} \boldsymbol{\beta}\left(\mathrm{ng} \mathrm{g}^{-\mathbf{1}}\right)$ \\
\hline DOXY & 5 & 24.7 & 29.3 \\
OTC & 5 & 28.1 & 36.3 \\
CTC & 5 & 25.5 & 30.9 \\
TETRA & 5 & 24.4 & 28.7 \\
STZ & 5 & 22.7 & 25.4 \\
SMZ & 5 & 24.6 & 29.3 \\
SDMX & 5 & 23.5 & 27.0 \\
ERY & 2.5 & 15.1 & 20.2 \\
TYL & 2.5 & 12.9 & 15.8 \\
\hline
\end{tabular}

Applicability could be determined in real samples obtained by FIS. Two samples were analyzed in 2016, 62 samples in 2017 and 44 samples until june 2018. Within these samples, one was detected with $14.24 \mathrm{ng}$ g-1 of TC.
This parameter is considered very important, since the value of the presented method can be demonstrated in the routine (Sttubings\& Bigwood, 2009). The method proposed in this work is easy and fast to perform. In addition, a large number of samples can be analyzed simultaneously.

\section{Conclusion}

The method developed and validated in this work was considered suitable for routine analysis, considering its simplicity and applicability. For honey samples, is very important to monitor TCs, SAs and MACROs, since these antibacterials are widely used in veterinary practices and apiculture. The parameters evaluated were in agreement with specifications for almost all analytes, considering the low concentrations used in validation procedure and the complexity of honey matrix. This LC-MS/MS, using low organic solvent consumption, associated with quickness and simplicity, offers advantages to professionals and contributes effectively to food safety. 


\section{References}

1. Al-Waili N, Salom K, Al-Ghandi A, Ansari JM. Antibiotic, pesticide, and microbial contaminants of honey: human health hazards. The scientific world jornal. 2012; 2012.

2. Anderson CR, Rupp HS, Wu WH. Complexities in tetracyclines analysis chemistry, matrix extraction, clenup, and liquid chromatography. Journal of chromatography A. 2005; 1075, 23-32.

3. Baquero F, Martínez JL, Cantón R. Antibiotics and antibiotic resistance in water environments. Current Option in biotechnology. 2008; 19(3), 260-265.

4. Barganska Z, Slebioda M, Namiesnik J. Determination of antibiotic residues in honey. Trends in analytical Chemistry. 2011; 30(7), 1035-1041.

5. Benetti C, Piro R, Binato G, Angeletti R, Riancotto G. Simultaneous determination of lincomycin and five macrolide antibiotic residues in honey by liquid chromatography coupled to electrospray ionization mass spectrometry. Food additives and contaminants. 2006; 23(11), 1099-1108.

6. Berendsen BJA, Stolker LAAM, Nielen MWF. Selectivity in the sample preparation for the analysis of drug residues in products of animal origin using LC-MS/MS. Trends in analytical chemistry.2013; 43, 229-239.

7. Boeckel TPV, Brower C, Gilbert M, Grenfell BT, Levin SA, Robinson TP, Teilland A, Laxminarayan R. Global trends in antimicrobial use in food animals. Agricultural sciences. Avalable at URL:

http://www.pnas.org/cgi/doi/10.1073/pnas. $1503141112,2015$.

8. Brasil. MAPA. Ministry of agricultural, livestock and supply. Manual of analytical quality assurance. $1^{\text {st }}$ ed., MAPA/ACS, Brasília, 2011.

9. Commission Decision 2002/657/EC. Implementing Council Directive 96/23/EC concerning the performance of analytical methods and interpretation of results.
Official jornal of Europeam communities. 2002; L239, 66-98.

10. Galarini R, Saluti G, Giusepponi D, Rossi $\mathrm{R}$, Monetti S. Multiclass determination of 27 antibioticas in honey. Food control. 2015; 48, 12-24.

11. Hammel Y, Mohamed R, Gremaud E, LeBreton M, Guy PA. Multiscreening approach to monitor and quantify 42 antibiotic residues in honey by liquid chromatography-tandem mass spectrometry. Journal of Chromatography. A. (2008); 1177(1), 58-76.

12. Kaufmann A, Roth S, Ryser B, Widmer M, Guggisberg D. Quantitative LC/MSMS determination of sulfonamides and some other antibiotics in honey. Journal of AOAC International. 2002; 85(4), 853860.

13. Kivrak I, Kivrak S, Harmandar. Development of a rapid method for the determination of antibiotic residues in honey using UPLC-ESI-MS/MS. Food Science and Technology. 2016; 36(1), 9096.

14. Kibroyesfa B and Haile N. Review on antibiotic residues in food of animal origin: economic and public health impacts. Applied jornal of hygiene. 2017; 6(1), 01-08.

15. Kümmerer K. Antibiotics in the aquatic environment - A review - Part I. Chemosphere. (2009). 75(4), 417-434.

16. Lee MH, Lee HJ, Ryu PD. Public health risks: chemical and antibiotic residuesreview. Asian-Australasian journal of animal sciences. 2001; 14(3), 402-413.

17. Lehotay SJ, Lightfield AR, HarmamFetcho JA, Donogue DJ. Analysis of pesticide residues in eggs by direct sample introduction/gas chromatography/tandem mass spectrometry. Journal of agricultural and food chemistry. 2001; 49, 4589-4596.

18. Lopez MI, Pettis JS, Smith IB, Chu PS. Multiclass determination and confirmation of antibiotic residues in honey using LCMS/MS. Journal of Agricultural and Food Chemistry. 2008; 56(5), 1553-1559.

19. Martinez-Vidal J L, Aguilera-Luiz MM, Romero-González R, Frenich AG. Multiclass analysis of antibiotic residues in 
honey by ultraperformance liquid chromatography-tandem mass spectrometry. Journal of Agricultural and Food Chemistry. (2009); 57(5), 17601767.

20. Normative Instruction (NI). Ministry of agricultural, livestock and supply. IN/09/2017.

21. Pan C, Zhang H, Chen S, Xuy Y, Jiang S. Determination of chloramphenicol residues in honey by monolithic column liquid chromatography-mass spectrometry after use of quechers clean up. Acta chromatographica. 2006; 17(17), 320-327.

22. Prestes OD, Friggi CA, Adaime MB, Zanella R. Um método moderno de preparo de amostra para determinação multirresídue de pesticidas por métodos cromatográficos acoplados espectrometria de massas. Química nova. 2009; 32(6), 1620-1634.

23. Sheridan R, Policastro B, Thomas S, Rice D. Analysis and occurence of 14 sulfonamide antibacterials and chloramphenicol in honey by solid-phase extraction followed by LC-MS/MS analysis. Journal of agricultural and food chemistry. 2008; 56, 3509-3516.

24. Sttubings G \& Bigwood T. The development and validation of a multiclass liquid chromatography tandem mass spectrometry (LC-MS/MS) procedure for the determination of veterinary drug residues in animal tissue using a QuEChERS (Quick, Easy, Cheap, Effective, Rugged and Safe) approach. Analytica Chimica Acta, 2009; 57, 1467 1480. 